\title{
Otoneurologic Findings in a Fishermen Population of the State of Santa Catarina: Preliminary Study
}

\author{
Bianca Simone Zeigelboim ${ }^{1,2}$ Thanara Pruner da Silva ${ }^{3}$ Hugo Carvalho ${ }^{2,4}$ \\ Diego Augusto de Brito Malucellii ${ }^{2,5}$ Claudia Giglio de Oliveira Gonçalves ${ }^{1}$ Evelyn Joyce Albizu ${ }^{6}$ \\ Paulo Breno Noronha Liberalesso ${ }^{2,7}$ Adriana Bender Moreira de Lacerda ${ }^{1,8}$ Gerusa Lopes Barilari 2,4
}

\footnotetext{
${ }^{1}$ Department of Speech-Language Pathology, Undergraduate Course and Communication Disorders Graduate Course at Universidade Tuiuti do Paraná-UTP, Curitiba, PR, Brazil

${ }^{2}$ Laboratory of Otoneurology, Universidade Tuiuti do Paraná-UTP, Curitiba, PR, Brazil

${ }^{3}$ Department of Surgery, Hospital das Clínicas, Universidade Federal do Paraná-UFPR, Curitiba, PR, Brazil

${ }^{4}$ Department of Speech-Language Pathology, UTP, Curitiba, PR, Brazil

${ }^{5}$ ENT at the Brazilian Red Cross Hospital, Curitiba, PR, Brazil

${ }^{6}$ Fundação Jorge Duprat Figueiredo de Segurança e Medicina do Trabalho do Ministério do Trabalho e Emprego (Ministry of Labor and Employment) - FUNDACENTRO/PR, Curitiba, PR, Brazil

${ }^{7}$ Neurologist at the Pequeno Principe Hospital and the Digital EEG Laboratory at the Brazilian Red Cross Hospital, Curitiba, PR Brazil

${ }^{8}$ Department of Communication Disorders from the University of Montreal, Montreal, QC, Canada
}

Address for correspondence Prof. Dra. Bianca Simone Zeigelboim, PhD, R. Gutemberg, 99-9th floor, Postal Code: 80420-030 Curitiba/ PR, Brazil (e-mail: bianca.zeigelboim@utp.br).

Int Arch Otorhinolaryngol 2014;18:6-10.
Abstract
Keywords
- dizziness
- vestibular function tests
- electronystag- mography
- chemical compounds
- occupational health

Introduction Fishing, one of the oldest productive activities, is an important sector of the national and world economy.

Aim To evaluate the vestibular behavior in a population of fishermen.

Methods In a retrospective and cross-sectional study, 13 fishermen (mean 45.0), between 33 and 62 years of age, were submitted to anamnesis, otorhinolaryngological evaluation, and vestibular exam through the vector electronystagmography.

Results The most evident otoneurologic symptoms were hearing loss (76.9\%), tinnitus (61.7\%), dizziness (46.1\%), and headache (46.1\%). The most evident clinical symptoms were fatigue $(46.1 \%)$, depression $(23.0 \%)$, anxiety $(15.3 \%)$, insomnia $(7.7 \%)$, and agitation during sleep (7.7\%). There were alterations in the vestibular exam in 5 fishermen (38.5\%) discovered in the caloric test. There was a prevalence of alteration in the peripheral vestibular system. There was a major frequency of the peripheral vestibular irritative syndrome.

Conclusion The otoneurologic complaints were frequent in the population studied to verify the importance of allowing labyrinth exams and the need for adopting preventive measures relating to noise exposure as well as carbon monoxide exposure, because they can cause and/or enhance various manifestations of labyrinthine vestibular impairment that can affect the quality of life of these workers. received

June 5, 2013

accepted

August 4, 2013
DOI http://dx.doi.org/

$10.1055 / \mathrm{s}-0033-1358584$ ISSN $1809-9777$.
Copyright $(2014$ by Thieme Publicações License terms

Ltda, Rio de Janeiro, Brazil
(ब(1) $\Theta \circledast$ 


\section{Introduction}

Fishing is one of the oldest productive activities and is an important sector of the Brazilian and world economy. ${ }^{1}$ The fishing industry is an important source of employment and exists in both traditional and industrial formats.

The industrial format, which is the focus of this study, occurs in vessels over $24 \mathrm{~m}$ long and the fisherman remains at sea for weeks on end-in most cases, with constant exposure to noise from the boat's engine, localized arm and whole body vibrations, as well as carbon monoxide (CO) and tobacco products, which can cause health problems both in general and in hearing. ${ }^{2}$

Among the illnesses that occur in this population, noiseinduced hearing loss (NIHL) should be highlighted. A study in Brazil with 52 industrial fishermen found $61.53 \%$ with below normal audiograms, with characteristics of NIHL and tinnitus reported by $46.15 \%$ of the fishermen evaluated. ${ }^{4}$ NIHL is caused by an accumulation of exposures to noise, usually daily, which are repeated continuously for a certain period. ${ }^{5}$

Nudelmann et $\mathrm{al}^{6}$ and Gonçalves ${ }^{7}$ suggest that NIHL is preventable and can have negative consequences of different natures, leading to hearing impairment, auditory dysfunctions such as tinnitus, and important vestibular changes. In Brazil, despite the evolution of knowledge and legislation about NIHL, there are still cases of injured workers. ${ }^{8}$

Exposure to $\mathrm{CO}$ can lead to both early and later neurologic side effects, which may occur as diffuse white matter demyelination and ischemic lesions of the globus pallidus. ${ }^{9,10}$ Exceeding 30 consecutive days of exposure can lead to chronic poisoning even in low concentrations. ${ }^{11} \mathrm{CO}$ poisoning can cause toxic effects such as insomnia, headaches, fatigue, decreased physical capacity, dizziness, vertigo, ataxia, mental impairment, nausea, vomiting, visual disturbances, hearing disorders, respiratory diseases, and other less frequent effects. ${ }^{10-13}$

Several studies emphasized the effects of the combined exposure of $\mathrm{CO}$ and noise. Some authors reported that simultaneous exposure to these two factors can lead to a potentiation of the effects of noise affecting not only the ears but also the mechanisms responsible for the body's balance. $^{14,15}$

The aim of this study was to evaluate the vestibular behavior in a population of fishermen.

\section{Materials and Methods}

We evaluated 13 male fishermen, from 33 to 62 years old (mean age 45.0 years), directed to us by the Jorge Duprat Figueiredo Foundation for Safety and Occupational Medicine (FUNDACENTRO) of the Ministry of Labor and Employment for the Otoneurology sector of an educational institution.

This was a cross-sectional study and the fishermen were evaluated irrespective of the time spent at sea. Included in the survey were fishermen without otoscopic alterations, and excluded were fishermen with musculoskeletal changes that prevented the examination.

The study was approved by the Institutional Ethics Committee under the Protocol number 094/2006 and after signing the consent form, the fishermen were subjected to the following procedures.

\section{Anamnesis}

A questionnaire was given with an emphasis on otoneurologic signs and symptoms.

\section{Ear, Nose, and Throat Evaluation}

Ear, nose, and throat examinations were performed to rule out any alteration that could affect the test.

\section{Vestibular Assessment}

The fishermen were subjected to the following tests that make up the vestibular examination. Initially, vertigo and position/positioning nystagmus, spontaneous and semispontaneous, were researched. Then, for a vector electronystagmography (VENG) a thermosensitive Berger Eletromedicina (São Paulo, SP, Brazil) model VN316 unit was used with three recording channels. An active electrode was attached with an electrolytic paste at a lateral angle for each eye and the frontal midline, forming an isosceles triangle, which allows the identification of horizontal, vertical, and oblique eye movements, and especially to allow the calculation of the angular velocity the slow component eye velocity (SCV) of the nystagmus. We used a Ferrante adjustable height swivel chair, a model EV VEC visual stimulator, and air calorimeter model NGR 05, both from Neurograff Eletromedicina (São Paulo, SP, Brazil).

We made the following eye and labyrinth tests at VENG, according to criteria proposed by Mangabeira-Albernaz et al. ${ }^{16}$

- Calibration of eye movements. At this stage of the examination, the clinical aspect evaluated was the regularity of motion, making the study data comparable.

- Study of spontaneous (eyes open and closed) and semispontaneous (eyes open) nystagmus. In this stage, we evaluated occurrence, direction, inhibitory effect of ocular fixation (IEOF), and the maximum SCV value of the nystagmus.

- Study of pendular tracking for evaluation of occurrence and type of curve.

- Study of optokinetic nystagmus at a speed of 60 degrees per second, horizontally counterclockwise and clockwise. We evaluated the occurrence, direction, maximum SCV counterclockwise and clockwise movements of the nystagmus.

- Study of pre- and postrotatory nystagmus in swivel chair testing, stimulating the lateral, anterior, and posterior semicircular canals. For stimulation of the lateral (horizontal) semicircular canals, the head was bent forward 30 degrees. In the next step, to sensitize the anterior and posterior (vertical) semicircular canals, the head was positioned 60 degrees backward and 45 degrees to the right, and then backward 60 degrees and 45 degrees to the left, respectively. The occurrence, direction, and counterclockwise and clockwise rotation frequency of the nystagmus was observed. 
- Study of pre- and postcaloric nystagmus was performed with the patient positioned so that the head and trunk were inclined 60 degrees backward for adequate stimulation of the lateral semicircular canals. The irrigation time of each ear with air at $42^{\circ} \mathrm{C}$ and $20^{\circ} \mathrm{C}$ lasted 80 seconds for each temperature, and the responses were recorded with eyes closed and then with eyes open to observe the IEOF. In this evaluation, the direction, the absolute values of the $\mathrm{SCV}$, and the relationship of directional preponderance and labyrinthine preponderance of postcaloric nystagmus were observed.

\section{Statistical Analysis}

We applied the difference of proportions test to compare the results of the vestibular exam (analyzing normal and abnormal results) and the Fisher test (correlating the results of the vestibular exam with the symptoms of hearing loss, tinnitus, and dizziness). The level for rejecting the null hypothesis was set at 0.05 or $5 \%$.

\section{Results}

The frequency of diverse otoneurologic and clinical signs and symptoms are seen in - Table $\mathbf{1}$.

The study of positional nystagmus, eye movement calibration, investigation of spontaneous nystagmus with eyes open and closed, semispontaneous nystagmus, pendular tracking, and optokinetic nystagmus showed no changes.

In the caloric test, there were 8 cases $(61.5 \%)$ of normal responses, 2 cases (15.4\%) of bilateral labyrinth hyperreflexia, 1 case $(7.7 \%)$ of unilateral labyrinth hyperreflexia, 1 case $(7.7 \%)$ unilateral labyrinth hyporeflexia, and 1 case (7.7\%) of bilateral

Table 1 Distribution of the frequency of otoneurologic signs and symptoms and clinical findings in 13 fishermen evaluated

\begin{tabular}{|c|c|c|}
\hline & $n$ & Frequency \\
\hline \multicolumn{3}{|l|}{ Otoneurologic signs and symptoms } \\
\hline Hearing loss & 10 & $76.9 \%$ \\
\hline Tinnitus & 8 & $61.5 \%$ \\
\hline Dizziness & 6 & $46.1 \%$ \\
\hline Headaches & 6 & $46.1 \%$ \\
\hline Imbalance when walking & 1 & $7.7 \%$ \\
\hline Difficulty or pain when moving neck & 1 & $7.7 \%$ \\
\hline Lightheadedness & 1 & $7.7 \%$ \\
\hline Cracking neck & 1 & $7.7 \%$ \\
\hline Sweating & 1 & $7.7 \%$ \\
\hline \multicolumn{3}{|l|}{ Diverse clinical signs and symptoms } \\
\hline Fatigue & 6 & $46.1 \%$ \\
\hline Depression & 3 & $23.0 \%$ \\
\hline Anxiety & 2 & $15.3 \%$ \\
\hline Insomnia & 1 & $7.7 \%$ \\
\hline Agitation during sleep & 1 & $7.7 \%$ \\
\hline
\end{tabular}

Table 2 Results obtained on caloric test analyzing absolute and relative values and the entrance exam for 13 fishermen evaluated

\begin{tabular}{|c|c|c|}
\hline & $n$ & Frequency \\
\hline \multicolumn{3}{|l|}{ Caloric test } \\
\hline Normoreflexia & 8 & $61.5 \%$ \\
\hline Bilateral labyrinth hyperreflexia & 2 & $15.4 \%$ \\
\hline Unilateral labyrinth hyporeflexia & 1 & $7.7 \%$ \\
\hline Unilateral labyrinth hyperreflexia & 1 & $7.7 \%$ \\
\hline Bilateral labyrinth hyporeflexia & 1 & $7.7 \%$ \\
\hline Vestibular exam & $\mathrm{N}$ & Frequency \\
\hline NVE & 8 & $61.5 \%$ \\
\hline PVID & 3 & $23.0 \%$ \\
\hline PVDD & 2 & $15.5 \%$ \\
\hline
\end{tabular}

Abbreviations: NVE, normal vestibular exam; PVID, peripheral vestibular irritative dysfunction; PVDD, peripheral vestibular deficit dysfunction. Note: The use of the proportions test demonstrates that there was no difference between the proportions of normal and abnormal exams $(p=0.2524)$.

labyrinth hyporeflexia, as shown in -Table 2. Five cases (38.4\%) were peripheral vestibular disorders, 2 cases (15.4\%) were peripheral vestibular deficit dysfunction, and 2 cases (23.0\%) were irritative peripheral vestibular dysfunction. The test was normal in 8 cases (61.5\%), as described in - Table 2.

The proportions test demonstrated that there was no difference between the proportions of normal and abnormal scans $(p=0.2524)$. The correlation between the results of the vestibular exam and hearing loss can be seen in -Table 3 . The Fisher test showed no significant difference between the proportions of patients with normal vestibular exams (NVE) and abnormal vestibular exams (AVE) with and without hearing loss $(p=0.1958)$. The correlation between the results of the vestibular exam and tinnitus can be seen in - Table 4. The Fisher test showed that there was no significant difference between the proportions of patients with NVE and AVE with and without tinnitus $(p=0.6845)$. The correlation between the results of the vestibular exam and dizziness can be seen

Table 3 Correlation between the results of vestibular exam and hearing loss in 13 fishermen evaluated

\begin{tabular}{|l|l|l|l|}
\hline \multirow{2}{*}{ Exam } & \multicolumn{2}{|c|}{$\begin{array}{c}\text { Otoneurologic } \\
\text { symptom }\end{array}$} & \multirow{2}{*}{ P } \\
\cline { 2 - 3 } & No & Yes & \\
\hline NVE & 3 & 5 & 0.1958 \\
\hline AVE & - & 5 & \\
\hline
\end{tabular}

Abbreviations: AVE, abnormal vestibular exam; NVE, normal vestibular exam.

Note: Fisher test showed no significant difference between the proportions of patients with NVE and AVE with and without hearing loss $(p=0.1958)$. 
Table 4 Correlation between the results of vestibular exam and tinnitus in 13 fishermen evaluated

\begin{tabular}{|l|l|l|l|}
\hline \multirow{2}{*}{ Exam } & \multicolumn{2}{|c|}{$\begin{array}{c}\text { Otoneurologic } \\
\text { symptom }\end{array}$} & \multirow{2}{*}{} \\
\cline { 2 - 3 } & No & Yes & \\
\hline NVE & 3 & 5 & 0.6845 \\
\hline AVE & 2 & 3 & \\
\hline
\end{tabular}

Abbreviations: AVE, abnormal vestibular exam; NVE, normal vestibular exam.

Fisher test showed no significant difference between the proportions of patients with NVE and AVE with and without tinnitus $(p=0.6845)$.

in - Table 5. The Fisher test also showed a significant difference between the proportions of patients with NVE and AVE with and without dizziness ( $p=0.0047)$.

\section{Discussion}

In analyzing the medical history, the occurrence of multiple diverse clinical and otoneurologic symptoms was verified. According to the literature, tinnitus is the first warning of exposure to excessive sound stimuli and may indicate an increased susceptibility to injury. This is an important symptom in preventing NIHL and is one of the main predictors of disadvantages generated in workers exposed to noise. Tinnitus is one of the three major otoneurologic manifestations, along with sensorineural hearing loss and dizziness. ${ }^{17}$ It is regarded as a physiologic disorder resulting from abnormal neural activity in the auditory pathways. ${ }^{18}$ Current conceptions suggest the existence of involvement of the peripheral and central auditory system, afferent and efferent, and the interaction with other systems. ${ }^{18}$ Dias et al $^{19}$ evaluated 284 workers and found a prevalence of $63.0 \%$ in NIHL and tinnitus in $48.0 \%$ of cases evaluated.

Studies done on 258 men from military service in Israel, exposed to intense impulse and impact noises, showed a vestibular dysfunction (not specifying type) when asymmetric hearing loss occurs. ${ }^{20}$ According to the authors, there is an association between the severity of hearing loss and vestibular symptoms.

Table 5 Correlation between the results of vestibular exam and dizziness in 13 fishermen evaluated

\begin{tabular}{|l|l|l|l|}
\hline \multirow{2}{*}{ Exam } & \multicolumn{2}{|c|}{$\begin{array}{c}\text { Otoneurologic } \\
\text { symptom }\end{array}$} & \multirow{2}{*}{$p$} \\
\cline { 2 - 3 } & No & Yes & \\
\hline NVE & 7 & 1 & 0.0047 \\
\hline AVE & - & 5 & \\
\hline
\end{tabular}

Abbreviations: AVE, abnormalvestibular exam; NVE, normal vestibular exam.

Note: Fisher test showed no significant difference between the proportions of patients with NVE and AVE with and without dizziness $(p=0.0047)$.
In the present study, we observed a change in the peripheral vestibular system in five patients; this change was found in the caloric test, with a predominance of irritative peripheral vestibular dysfunction. In the literature, there was a scarcity of studies involving the vestibular system and the activity of fishing. We emphasize the research of the Kumar et al, ${ }^{15}$ who applied vestibular evoked myogenic potentials in individuals with NIHL and observed significant changes in elongation and reduction of n23 latency in p13-n23 intervals, thus demonstrating an involvement of this important otoneurologic examination. Vestibular evoked myogenic potential was abnormal in $67.0 \%$ of cases with NIHL. The authors concluded that the possibility of vestibular dysfunction, especially in the saccule, is high in these cases.

With respect to $\mathrm{CO}$ poisoning, Kowalska ${ }^{21}$ studied 50 patients and showed bilateral hearing loss in different degrees in $42.0 \%$, retrocochlear impairment in $80.0 \%$, deafness in $6.0 \%$, and vestibular dysfunction in $86.0 \%$ of patients. In another study conducted on workers exposed to CO, $66.0 \%$ had hearing loss and $76.5 \%$ had vestibular dysfunction. ${ }^{22}$ According to the author, these data confirm the toxic effects of $\mathrm{CO}$.

When comparing the results of the vestibular exam with complaints of dizziness, this difference becomes relevant. According to Cohen, ${ }^{23}$ dizziness may hinder the performance of the individual in performing activities requiring rapid movements of the head and also on tasks involving trunk and head flexion. This explains the significance we encountered occurring with dizziness, because this type of profession sometimes requires jerky movements of the trunk and head.

In the literature, we found few Brazilian and international references that address the study of vestibulometry in industrial fishermen to compare our findings, which demonstrates the relevance of the subject studied, thus encouraging the continuation of this research and the realization of new studies on the subject, so that we may, in the near future, plan actions that can minimize the symptoms caused in the performance of this profession.

\section{Conclusions}

The most evident otoneurologic symptoms were hearing loss, tinnitus, dizziness, and headache, and several more clinical symptoms were reported including fatigue, depression, anxiety, insomnia, and restlessness during sleep.

Alterations in the vestibular exam occurred in $38.4 \%$ of fishermen, found in the caloric test, with predominant dysfunction of the peripheral vestibular system of the irritative type.

The otoneurologic complaints were frequent in the population studied and verify the importance of allowing labyrinth exams and the need for adopting preventive measures relating to exposure to noise and carbon monoxide, as they can cause and/or enhance various manifestations such as labyrinthine vestibular impairment that can affect the quality of life of these workers. 
10 Otoneurologic Findings in a Fishermen Population Zeigelboim et al.

\section{References}

1 Neitzel RL, Berna BE, Seixas NS. Noise exposures aboard catcher/ processor fishing vessels. Am J Ind Med 2006;49(8):624-633

2 Axelsson A, Arvidsson I, Jerson T. Hearing in fishermen and coastguards. In: Salvi RJ, Henderson D, Hamernik RP, eds. Basic and Applied Aspects of Noise-Induced Hearing Loss. NATO Science Series Life Sciences; 2006

3 Paini MC, Morata TC, Corteletti LJ, Albizu E, Marques JM, Santos L. Audiological findings among workers from Brazilian small-scale fisheries. Ear Hear 2009;30(1):8-15

4 Heupa AB, Gonçalves CGO, Albizu EJ, Iantas MR, Lacerda ABM, Lobato DC. Programa de prevenção de perdas auditivas em pescadores: perfil auditivo e ações educativas. Rev CEFAC 2011;13(6):109-116

5 Comitê Nacional de Ruído e Conservação Auditiva. Boletim n. 6. Diretrizes Básicas de um Programa de Conservação Auditiva. 1999. Available at: http://saudetrabalho.sites.uol.com.br/PAIR/Comite_Nac_ruid_cons_audB6.pdf. Accessed Arpil 4, 2012

6 Nudelmann AA, Costa EA, Seligman J, Ibañez RN. Atualização sobre os documentos do Comitê Nacional de Ruído e Conservação Auditiva. In: Nudelmann AA, Costa EA, Seligman J, Ibañez RN, eds. PAIR-Perda auditiva induzida pelo ruído. Rio de Janeiro, Brasil: Revinter; 2001:225-234

7 Gonçalves CGO. Saúde do trabalhador: da estruturação à avaliação de Programas de Preservação Auditiva. São Paulo, Brasil: Roca; 2009

8 Gonçalves CGO, Iguti AM. Análise de programas de preservação da audição em quatro indústrias metalúrgicas de Piracicaba, São Paulo, Brasil. Cad Saude Publica 2006;22(3):609-618

9 Alioglu Z, Sari A, Aynaci M, Velioglu SK, Oznenoglu M. Neurological symptoms after carbon monoxide intoxication. J Neurol Sci 1999; 16(4):18-20

10 Kaimen-Maciel DR, Rocha FHB, Mancini DA. Desmielinização tardia após intoxicação por monóxido de carbono. Rev Neurocienc 2010;18(1):66-68
11 Penney DG. Chronic carbon monoxide poisoning. In: Penney DG, ed. Carbon Monoxide Toxicity. Boca Raton, FL: CRC Press; 2000: 394-420

12 Choi IS. Delayed neurologic sequelae in carbon monoxide intoxication. Arch Neurol 1983;40(7):433-435

13 Prockop LD, Chichkova RI. Carbon monoxide intoxication: an updated review. J Neurol Sci 2007;262(1-2):122-130

14 Fechter LD. Mechanistic basis for interactions between noise and chemical exposure. ACES 1989;1(1):23-28

15 Kumar K, Vivarthini CJ, Bhat JS. Vestibular evoked myogenic potential in noise-induced hearing loss. Noise Health 2010; 12(48):191-194

16 Mangabeira-Albernaz PL, Ganança MM, Pontes PAL. Modelo operacional do aparelho vestibular. In: Mangabeira-Albernaz PL, Ganança MM, eds. Vertigem. $2^{\mathrm{a}}$ ed. São Paulo, Brasil: Moderna; 1976:29-36

17 Fukuda Y. Zumbido: diagnóstico e tratamento. Rev Bras Med Otorrinolaringol 1997;4(2):39-43

18 Jastreboff PJ. Phantom auditory perception (tinnitus): mechanisms of generation and perception. Neurosci Res 1990;8(4): 221-254

19 Dias A, Cordeiro R, Corrente JE, Gonçalves CGO. Associação entre perda auditiva induzida pelo ruído e zumbidos. Cad Saude Publica 2006;22(1):63-68

20 Golz A, Westerman ST, Westerman LM, et al. The effects of noise on the vestibular system. Am J Otolaryngol 2001;22(3):190-196

21 Kowalska S. [State of the organ of hearing and equilibrium in acute carbon monoxide poisoning]. Med Pr 1980;31(1):63-69

22 Kowalska S. [State of the hearing and equilibrium organs in workers exposed to carbon monoxide]. Med Pr 1981;32(2): 145-151

23 Cohen H. Vestibular rehabilitation improves daily life function. Am J Occup Ther 1994;48(10):919-925 